\title{
A LEI DE INCENTIVO FISCAL E O (NÃO) DIREITO AO ESPORTE NO BRASIL
}

THE LAW OF TAX INCENTIVE AND THE (ABSENCE OF THE) RIGHT TO SPORT IN BRAZIL

\author{
LA LEY DE INCENTIVO TRIBUTARIO Y EL DERECHO (NO) A LOS DEPORTES EN \\ BRASIL
}

\section{Wagner Barbosa Matias*, Pedro Fernando Athayde**, Edson Marcelo Húngaro**, Fernando Mascarenhas**}

\section{Palavras-chave}

Financiamento governamental. Esportes. Legislação.

Keywords

State.

Financing,

Government

Sports.

Legislation.

Palabras clave

Estado.

Financiación gubernamental. Deportes.

Legislación.
Resumo: 0 presente estudo aborda a aplicação orçamentária da Lei de Incentivo ao Esporte (Lei no. 11.438/2006). De cunho quantitativo-qualitativo, a investigação tem suporte em levantamento documental. 0 debate teórico foi realizado a partir das seguintes categorias: Estado; fundo público; direitos sociais; políticas esportivas. Fez-se uma pesquisa empírica nos documentos oficiais publicados pelo Ministério do Esporte. Para a análise dos dados, foram privilegiados os aspectos apontados a seguir: configuração e abrangência dos direitos; configuração do financiamento e gasto. Identificou-se a incompatibilidade da referida Lei e a garantia do acesso ao esporte como direito social.

Abstract: This study addresses the budgetary enforcement of the Sports Incentive Law (Law 11.438 of 2006). Under a quantitative-qualitative approach, this research is supported by document survey. The theoretical debate was based on the following categories: State; public fund; social rights; sports policy. Empirical research was conducted in official documents published by the Ministry of Sports. Data analysis focused on the following aspects: configuration and scope of rights; configuration of funding and spending. Incompatibility was found between the Law and ensuring access to the sport as a social right.

Resumen: El presente estudio aborda la aplicación presupuestaria de la Ley de Incentivo al Deporte (Ley no. 11.438/2006). Con carácter cuantitativo-cualitativo, la investigación tiene el soporte un levantamiento documental. El debate teórico se realizó desde las siguientes categorías: Estado; fondo público; derechos sociales; políticas deportivas. Se realizó una investigación empírica en los documentos oficiales publicados por el Ministerio del Deporte. Para el análisis de los datos, se privilegiaron los aspectos señalados a continuación: configuración y amplitud de los derechos; configuración de la financiación y gastos. Se identificó la incompatibilidad entre la referida Ley y la garantía del acceso al deporte como derecho social.
* Ministério do Esporte. Brasília, DF, Brasil.

E-mail: wagner.matias@outlook.com

** Universidade de Brasília. Brasília, DF, Brasil.

E-mail: pedroavalone@gmail.com

Recebido em: 13-04-2014 Aprovado em: 21-01-2015 


\section{INTRODUÇÃO}

Um dos elementos utilizados pelo governo Lula para justificar a criação do Ministério do Esporte (ME) foi o financiamento restrito para o setor esportivo. Conforme análise governamental, tal limitação orçamentária devia-se, entre outros fatores, à inexistência de uma política de financiamento que garantisse a diversificação de recursos, inclusive, aqueles oriundos de isenção fiscal. Entretanto, embora constasse da agenda do ME desde $2003^{1}$, tendo sido discutida na I e II Conferências Nacionais do Esporte (BRASIL, 2004; 2006), a Lei de Incentivo ao Esporte (LIE) (Lei n. 11.438) foi sancionada em 29 de dezembro de 2006, sendo regulamentada em 3 de agosto de 2007 por meio do Decreto ํ․ 6.180.

Tal ditame autoriza que, no período de 2007 a 2015, sejam deduzidos do Imposto de Renda (IR) valores despendidos por pessoas físicas (até 6\%) e jurídicas (até 1\%), a título de patrocínios ou doações a projetos desportivos e paradesportivos.

A III Conferência Nacional do Esporte (BRASIL, 2010) indicou a prorrogação da LIE até 2025. No entanto, no Projeto de Lei (PL) n־. 5.036/2013, que tramita no Congresso Nacional (CN), consta a extensão até 2020, com ampliação dos percentuais de dedução das pessoas jurídicas de $1 \%$ para $4 \%$ do IR devido.

Destaca-se que a LIE segue as mesmas medidas de incentivos fiscais implementadas para a cultura: Lei Rouanet (Lei no. 8.313/1991) e Lei do Audiovisual (Lei n. 8.685/1993). $E$, tanto no esporte como na cultura, tais ditames se inserem no processo de desresponsabilização do Estado para o financiamento e execução das políticas sociais que garantem direitos de cidadania.

Nesse sentido, cabe perguntar: como se configura o direito ao esporte a partir de tal mecanismo de financiamento? Qual é o direcionamento dos recursos advindos da LIE? Quem são os principais patrocinadores e/ou doadores e beneficiados? 0 objetivo da investigação foi analisar a aplicação orçamentária da LIE e sua relação com o (não) direito ao esporte no país.

\section{DELINEAMENTO DO ESTUDO}

As pesquisas no âmbito do financiamento do esporte no Brasil são incipientes e, sobre a LIE, ainda pouco expressivas. Os estudos de Bastidas e Bastos (2011), Cavazzoni, Bastos e Kurle (2010) e França Junior e Frasson (2010) se apresentam como iniciativas de investigação sobre o referido tema.

O presente estudo se caracteriza como uma pesquisa social de nível exploratório, uma vez que a literatura científica revela que tal temática ainda carece de estudos. A abordagem escolhida foi de caráter quantitativo-qualitativo, que se apoia no levantamento documental.

O debate teórico foi realizado a partir das seguintes categorias: Estado; fundo público; direitos sociais; políticas esportivas. Já a pesquisa empírica teve como fonte documentos oficiais publicados pelo ME.

$O$ recorte do estudo compreende o período de 3 de agosto de 2007 (quando da regulamentação da LIE) a 3 de agosto de 2013 (exatos seis anos de vigência da referida Lei). Já a

1 Agnelo Queiroz, então Ministro do Esporte, afirmou em audiência na Câmara dos Deputados (CD) em 19 de setembro de 2003 : "O presidente já anunciou o interesse na aprovação desta Lei, que vai significar a segunda grande revolução do esporte brasileiro. Nós já estamos estudando o formato dela, que será um incentivo com abatimento de imposto de renda de pessoa física e jurídica". "Agnelo pede na Câmara a aprovação da lei de incentivo fiscal para o esporte", 19 de setembro de 2003. (AGNELO, p. 1, 2003). 
análise e a discussão dos dados se concentraram na configuração e abrangência dos direitos e benefícios e na configuração do financiamento e gasto, especificamente sobre a "magnitude e direção do gasto", conforme sinaliza Boschetti (2009).

Para a apresentação dos dados, discussão e conclusão, o texto articula os seguintes momentos: o contexto das leis de incentivo; a política esportiva (no que se refere ao financiamento do esporte no país); e a LIE.

\section{ESTADO, FUNDO PÚBLICO E DIREITO SOCIAL}

Poulantzas (2000, p. 130) entende o Estado "[...] como uma relação, mais exatamente como a condensação material de uma relação de forças entre classes e frações de classe". Na visão do autor, o Estado não é monolítico e se configura como um campo de disputas, com ações determinadas pela correlação de forças.

Ao longo século XX, a atuação do Estado refletiu a correlação de forças existentes nas diferentes nações. No pós-Segunda Guerra Mundial até meados da década de 1970, como resultado da pressão dos trabalhadores e diante da queda da acumulação de capital, foi possível observar em diversas nações um Estado com uma feição social: o Welfare State, que se caracterizou pela "[...] intervenção na economia de mercado que, ao contrário do modelo liberal que o antecedeu, fortaleceu e expandiu o setor público e implantou e geriu sistemas de proteção social" (PEREIRA, 2011, p. 23).

Com o Welfare State, observou-se, pela primeira vez, conforme a correlação de forças entre as classes sociais nos países, que os membros da burguesia passaram a pagar impostos, especialmente com o mecanismo de progressividade sobre a renda e as posses; os trabalhadores e os pobres em situação de pauperização se beneficiaram com serviços públicos e com os programas de transferência de renda (SALVADOR, 2010).

No entanto, a partir dos anos 1970, cresceram as críticas dos liberais e neoliberais ao padrão de financiamento do Welfare State e, diante de mais uma crise do modo de produção capitalista, a burguesia começou a "[...] destruir a relação do fundo público com a estrutura de salários, com a correção das desigualdades e dos bolsões de pobreza" (OLIVEIRA, 1998, p. 46), deixando a população de baixa renda relegada à caridade pública ou a uma ação estatal evasiva e eventual.

Em tal momento histórico tem-se, portanto, uma expansão do poder da burguesia e uma retração da força dos trabalhadores. Com efeito, há uma diminuição do fundo público na garantia dos direitos sociais e ampliação da presença do Estado no atendimento das necessidades do capital².

O Brasil, com um Welfare State que beneficiou basicamente os trabalhadores urbanos, por meio de um gasto residual com base em um sistema tributário regressivo e com um sistema não distributivo e concentrador de renda (KORNIS, 1994 apud FIORI, 2001), aderiu tardiamente à agenda pró-mercado.

2 A necessidade básica do capital é o lucro. Para a sua produção, devem-se satisfazer suas necessidades intermediárias, que equivalem aos sistemas legal e monetário, às infraestruturas coletivas de transporte e à transformação da população em assalariados e consumidores (JUNIOR; PEREIRA, 2013, p. 8, grifos dos autores). 
De fato, as ideias neoliberais de livre circulação de capital, de câmbio flutuante, de contenção de gastos sociais, de privatização e de transferências dos serviços públicos para 0 setor privado ou para entidades do chamado "Terceiro Setor" somente ganham destaque com a posse de Fernando Collor, em 1989, e se consolidam no governo de Fernando Henrique Cardoso.

É nesse cenário de diminuição do papel do Estado no âmbito social e de maximização para o capital que se proliferam as leis de incentivo. No Brasil, de acordo com Piva (2013, p. 297):

\begin{abstract}
0 sistema de financiamento com ênfase na renúncia fiscal foi impulsionado pela defesa da necessidade de se criar uma cultura de patrocínio privado, que derivou de um discurso ideológico sobre a capacidade do Estado de gerir investimentos em cultura. Este foi o resultado de dois contíguos: do neoliberalismo contra o Estado do início da década de 1990; e da memória aos abusos do Estado autoritário dos anos 1970 e 1980, atribuindo ao mercado à decisão sobre onde e como investir.
\end{abstract}

A primeira experiência de renúncia fiscal no país foi inaugurada pela Lei Sarney (Lei no. 7.502/1986), que visava incentivar o investimento privado nas artes, criando o Fundo de Promoção Cultural. No governo Collor, em 1991, a Lei Sarney foi revogada com a criação da Lei Rouanet (Lei no. 8.313/1991), e regulamentada, em 1995, no governo de Fernando Henrique Cardoso. Em 1993, no governo Itamar Franco, tem-se a sanção de uma Lei específica de renúncia fiscal para o setor de audiovisual (Lei no. 8.685/1993). Conforme Augustin (2010, p. 47), uma diferença que pode ser observada entre a Lei de Audiovisual para a Lei Rouanet é que:

O investimento através da lei de investimento do audiovisual, além de ter 100\% de benefício fiscal, ainda pode ser lançado como despesa operacional. Desse modo, o subsídio acaba sendo $125 \%$. Ou seja, se com a Rouanet a empresa faz propaganda de graça, com a Lei do Audiovisual ela faz propaganda de graça e ainda recebe dinheiro do governo em troca. Além de receber esse incentivo extra de $25 \%$, a empresa investidora tem direitos sobre os lucros do filme, na proporção do valor investido. Em caso de prejuízo, a empresa não perde nada.

Em 2006, o presidente Lula sanciona a Lei de Incentivo ao Esporte (LIE) (Lei nº. 11.438/2006), e, em 2007, a Lei de Incentivo à Pesquisa (Lei no. 11.487/2007). Tais dispositivos legais, juntamente com aqueles já existentes, aumentaram os recursos para o esporte, para a pesquisa e para a cultura, respectivamente. No entanto, é falsa a noção de ampliação do acesso dos cidadãos aos direitos constitucionais, pois é o setor privado que deixa de pagar os impostos e faz uso do recurso, conforme seus interesses, reforçando a focalização das políticas sociais e a sua marca perante o público.

$O$ fato é que a LIE, objeto da presente investigação, se insere no conjunto de medidas de contrarreforma do Estado brasileiro, iniciada na década de 1990 pelas frações da burguesia, com o objetivo de apropriar-se do fundo público e retirar o protagonismo do Estado no desenvolvimento de políticas sociais.

\title{
4 A POLÍTICA ESPORTIVA NO BRASIL
}

A partir da Constituição Federal (CF) de 1988, o esporte passa a figurar como um direito social. No entanto, a relação com o Estado vem desde o período do Estado Novo, com o Decreto n. 3.199/1941. 
Naquele período, o Estado tinha o papel de disciplinar e fiscalizar a organização e a prática esportiva no país (MANHÃES, 2002). Até 1969, o financiamento do esporte era realizado por meio de concessões ordinárias e extraordinárias, subvenções e isenções. No entanto, com o regime militar, foi implantado um padrão de financiamento mais robusto e regular. 0 Decreto-Lei n-. 594/1969 instituiu a Loteria Esportiva Federal, destinando 30\% de seus rendimentos líquidos para programas de Educação Física e atividades esportivas (BUENO, 2010).

Em 1975, é formulada a nova Lei (Lei №. 6.251) do setor esportivo, regulamentada em 1977 pelo Decreto ํ‥ 80.228. Para Manhães (2002), não houve mudança substancial em relação ao Decreto anterior, mas apenas alterações periféricas. Castelanni Filho (2008, p. 135) aponta que as alterações reproduziram "[...] os parâmetros de 1941 e os modernizou tão somente naquilo que se fazia necessário para o atendimento dos interesses do campo do marketing e do campo do esporte classista".

Com o fim da ditadura militar, em 1985, começa a florescer no país uma nova república. A Carta Magna elaborada no Governo Sarney, em 1988, registra algumas conquistas para os trabalhadores, mas surge no momento em que o mundo discute e implementa um modelo de regulação social bem diferente do Welfare State.

No âmbito esportivo, a CF de 1988, ao passo que estabelece o esporte como um direito do cidadão e dever do Estado, concede autonomia para as entidades esportivas, cedendo à pressão destas e do mercado por mais liberdade de atuação, tendo em vista que, à época, o Conselho Nacional de Desportos (CND) ainda detinha plenos poderes de intervenção. $O$ Estado, assim, deixa de ser o protagonista, abandonando o "intervencionismo" político característico das legislações anteriores. A administração pública continuou a financiar o esporte de alto rendimento, mas a gestão e o estabelecimento de critérios de distribuição dos recursos ficavam a cargo das Federações, Confederações e do Comitê Olímpico Brasileiro (COB) (CASTELLANI FILHO, 2008).

A liberalização do esporte, principalmente do futebol para o mercado, ocorre com a edição da Lei Zico (Lei no. 8.672/1993) e, posteriormente, com a Lei Pelé (Lei no. 9.615/1998), que seguem a tendência europeia de disciplinarem e normatizarem a prática esportiva profissional. Tais ditames demarcaram mudanças no tratamento comercial do esporte, sinalizando para a incorporação de parâmetros empresariais na administração dos clubes e associações esportivas, bem como na comercialização de atletas.

A Lei Zico e a Lei Pelé não alteraram o padrão de financiamento do esporte no país, porém, permitiram a exploração do jogo de bingo pelos clubes de futebol ${ }^{3}$. As mudanças produzidas pelos referidos ordenamentos legais não contribuíram para a garantia do esporte como direito, mas, sim, legitimaram a hegemonia dos interesses econômico-corporativos no âmbito esportivo.

Após o fracasso do Brasil no quadro de medalhas nos Jogos Olímpicos de Sidney, em 2000, o governo FHC sancionou, em 2001, a Lei no. 10.264, denominada Lei Agnelo-Piva, por ser de autoria do então deputado federal Agnelo Queiroz e do senador Pedro Piva.

A Lei modificou parte do art. 56을 da Lei Pelé, que trata dos recursos para o esporte. Especificamente, mudou a redação do inc. VI, que tratava de "outras fontes", para "dois por

3 O Presidente Lula, através da Medida Provisória (MP) nº. 168/2004, após o escândalo dos bingos, decretou a proibição do jogo de bingo no país. 
cento da arrecadação brutas dos concursos de prognósticos e loterias federais e similares cuja realização estiver sujeita a autorização federal, deduzindo-se este valor do montante destinado aos prêmios". Destes recursos, 85\% são destinados ao COB e 15\% ao Comitê Paraolímpico Brasileiro (CPB). Contudo, deste total repassado para as duas entidades, 10\% deverão ser investidos no desporto escolar e 5\% no desporto universitário.

O ciclo do governo de FHC chegou ao fim em 2002, e, no ano seguinte, Lula assumiu a Presidência da República. $O$ governo Lula criou uma pasta exclusiva para o esporte. $\mathrm{O}$ Ministério do Esporte (ME) surge com a missão de "formular e implementar políticas públicas inclusivas e de afirmação do esporte e do lazer como direitos sociais dos cidadãos, colaborando para o desenvolvimento nacional e humano (BRASIL, 2003, p. 1).

No entanto, apesar dos acenos nos primeiros anos de governo em direção à implementação de políticas esportivas, balizados sobre o princípio do direito universal ao esporte, tal fato não se materializou no ordenamento legal e no financiamento (MATIAS, 2013). 0 que se observou foi o estreitamento e consolidação dos laços entre o Governo Federal, as entidades esportivas e o setor privado, que se deu por meio da sanção do Estatuto de Defesa do Torcedor (Lei ํ‥ 10.671/2003), da criação do programa Bolsa Atleta (Lei no. 10.891/2004), da criação da Timemania (Lei no. 11.345/2006) e com a Lei de Incentivo ao Esporte (LIE) (Lei no. 11.438/2006), e se acentuou com a entrada do Brasil no circuito de megaeventos esportivos.

Ainda no que se refere ao financiamento do esporte, nota-se, como resultado da chegada dos megaeventos, o aumento dos repasses diretos do governo para as entidades esportivas e o crescimento das verbas de patrocínios das empresas estatais (MATIAS, 2013).

Se na década de 1930 os atletas brasileiros deixavam de ir competir nos Jogos Olímpicos por falta de recursos, esse problema não existe mais. Sem dúvida, houve um aumento significativo nas fontes de financiamento do esporte, principalmente para 0 alto rendimento. $E$ um dos mecanismos implementados que contribuíram para tal crescimento foi a LIE.

\section{A LEI DE INCENTIVO AO ESPORTE: A HEGEMONIA DO ESPORTE DE ALTO RENDIMENTO}

A Lei de Incentivo ao Esporte (LIE) (Lei no. 11.438/2006) é uma forma simplificada de uso dos recursos do fundo público, uma vez que estes não seguem os "trâmites e controles orçamentários estabelecidos, sendo executados diretamente por organizações não governamentais ou entes governamentais fora da esfera federal. Além disso, tais recursos não se submetem a eventuais contingenciamentos de despesa pelo Poder Executivo" (TRIBUNAL DE CONTAS DA UNIÃO, 2013, p. 2).

A legislação em vigor autoriza as pessoas físicas a descontar até $6 \%$ do imposto devido, e as pessoas jurídicas tributadas com base no lucro real, até 1\%. No período aqui estudado, as contribuições são realizadas quase que exclusivamente pelas empresas. Em 2012, por exemplo - único ano em que o número de contribuições individuais (1.090) foi maior que o número de empresas que doaram (1.077) - as pessoas físicas investiram $\mathrm{R} \$ 4,3$ milhões e as pessoas jurídicas renunciaram o montante de $\mathrm{R} \$ 207,3$ milhões $^{4}$. Na Figura 1, exposta a seguir, tem-se o volume total aprovado e o volume efetivamente captado durante o período pesquisado.

4 "Pela primeira vez, apoio individual ao esporte supera o de empresas." Disponível em: www.esporte.gov.br. Acesso em: 3 out./2013. 
Ao analisar o conjunto de empresas que doaram por meio da LIE, percebe-se a hegemonia dos setores financeiros, petrolíferos e minerador. As três principais corporações doadoras são, respectivamente: Bradesco ( $\mathrm{R} \$ 88,8$ milhões), Petrobrás ( $\mathrm{R} \$ 87,5$ milhões) e Vale ( $\mathrm{R} \$$ 74,7 milhões).

No período aqui pesquisado, foram aprovados pela comissão técnica do ME exatamente dois mil projetos ${ }^{5}$, sendo que o montante autorizado para captação foi de $\mathrm{R} \$ 2,5$ bilhões. Contudo, efetivamente só foi captada pelos proponentes a soma de $\mathrm{R} \$ 950,4$ milhões, ou seja, $36,6 \%$ do autorizado.

Figura 1 - Valor autorizado x valor captado no período de 2007 a 2013, em milhões de $R \$$.

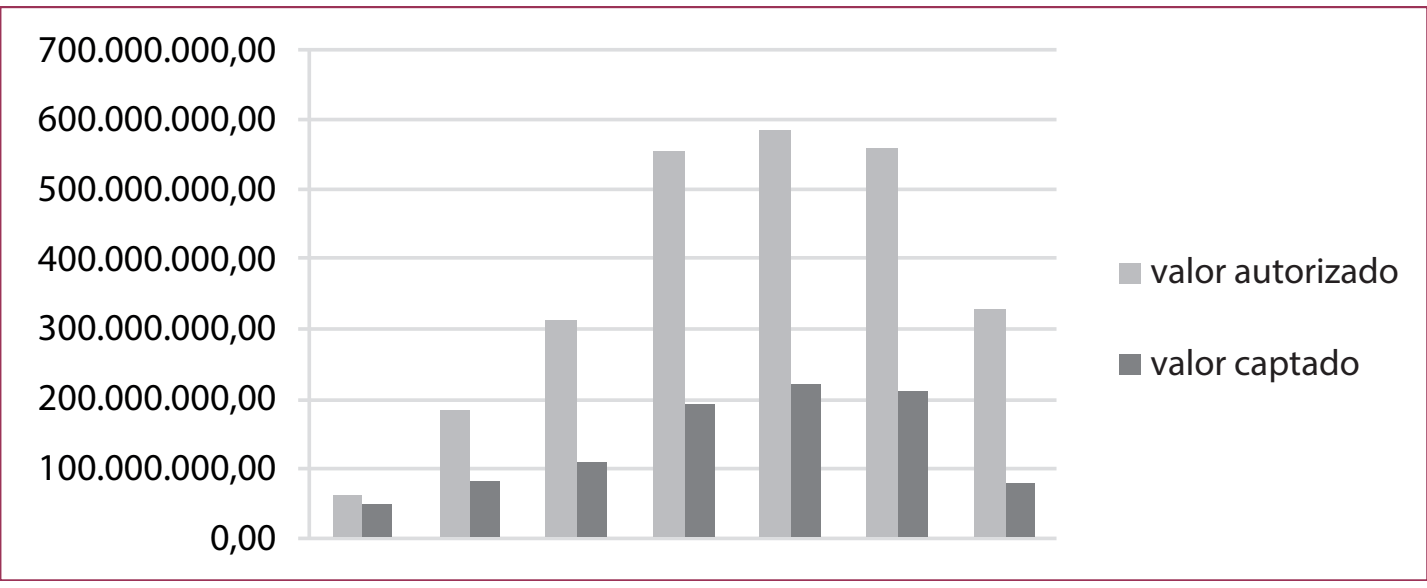

Fonte: Ministério do Esporte. Elaboração dos autores (2014).

A aprovação de um projeto na etapa de análise técnica não garante aos proponentes 0 recebimento do recurso. Apesar de este possuir alcunha pública, quem decide se vale a pena aplicá-lo são as empresas. Além do retorno de mercado, outros aspectos podem contribuir para o baixo valor de captação, tais como: a falta de capacidade técnica dos proponentes; a falta de análise da viabilidade financeira por parte da Comissão Técnica da LIE; e o limite de dedução para empresa.

De qualquer forma, nota-se um aumento do volume de recursos tanto no que se refere aos projetos aprovados como aos captados. Apenas em 2012 houve uma pequena queda em relação aos outros anos ${ }^{6}$.

Vale ressaltar que, no conjunto das políticas esportivas, a LIE amplia os recursos para o setor, todavia, tal mecanismo fornece um caráter mercantil à temática esportiva quando deixa para o mercado (normalmente o setor de marketing das empresas) definir o projeto que deverá receber o financiamento.

Destaca-se que o crescimento do volume de recursos se deu conjuntamente com 0 aumento do número de projetos aprovados. No período de 2007 a 2013, identificaram-se 442 propostas para o desenvolvimento do esporte educacional (ED), 391 propostas para o esporte participação (EP) e 1.187 propostas para o esporte de rendimento $(E R)^{7}$.

5 Dados disponíveis em: www.esporte.gov.br. Acesso em: 1 out. 2013

6 Já em 2013, no presente estudo fez-se uso somente daqueles dados disponíveis até 8 de agosto de 2013, não sendo possível apontar uma diminuição dos valores.

7 Cabe observar que a LIE veda a apresentação de mais de seis projetos por proponente. Contudo, em 2010, por exemplo, a Confederação Brasileira de Desportos Aquáticos (CBDA) e o Instituto Brasil tiveram nove propostas aprovadas. 
Figura 2 - Número de propostas aprovadas por manifestação esportiva.

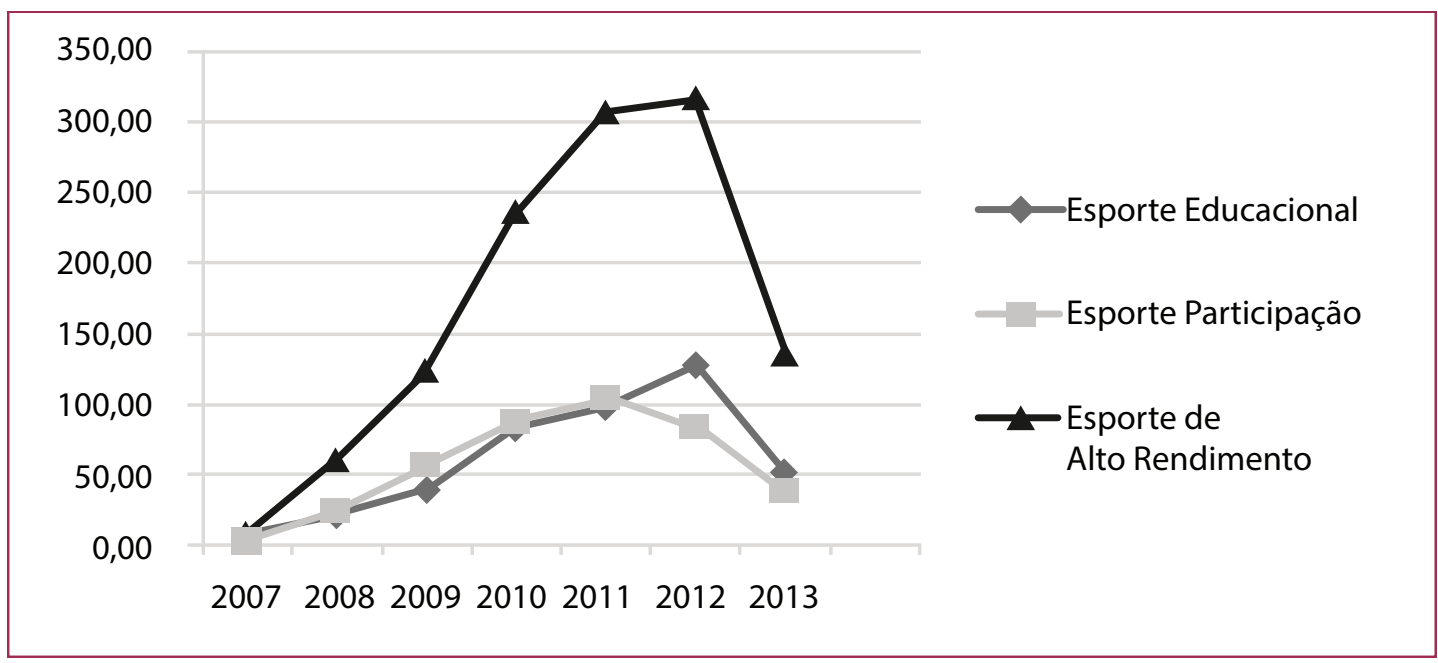

Fonte: Ministério do Esporte. Elaboração dos autores (2014).

Nota-se a hegemonia de propostas para o ER, o que se observa também no volume de recursos aprovados e captados. Enquanto os projetos para o ED e EP captaram juntosR $\$$ 320,8 milhões, os projetos do ER somaram o total de $\mathrm{R} \$ 647,5$ milhões (Figura 3). Em outras palavras, mais de $50 \%$ dos recursos captados por meio da LIE foi destinado à manifestação esportiva de mais visibilidade perante o público.

A LIE acentua a destinação de recursos para o ER que atende uma pequena parcela da população e beneficia os setores conservadores do esporte e a grande indústria esportiva e do entretenimento. Portanto, a prioridade de financiamento são os projetos do ER que possibilitam um maior retorno de mídia e consequentemente de mercado.

Figura 3 - Valor autorizado e captado x manifestação esportiva, em milhões de R\$

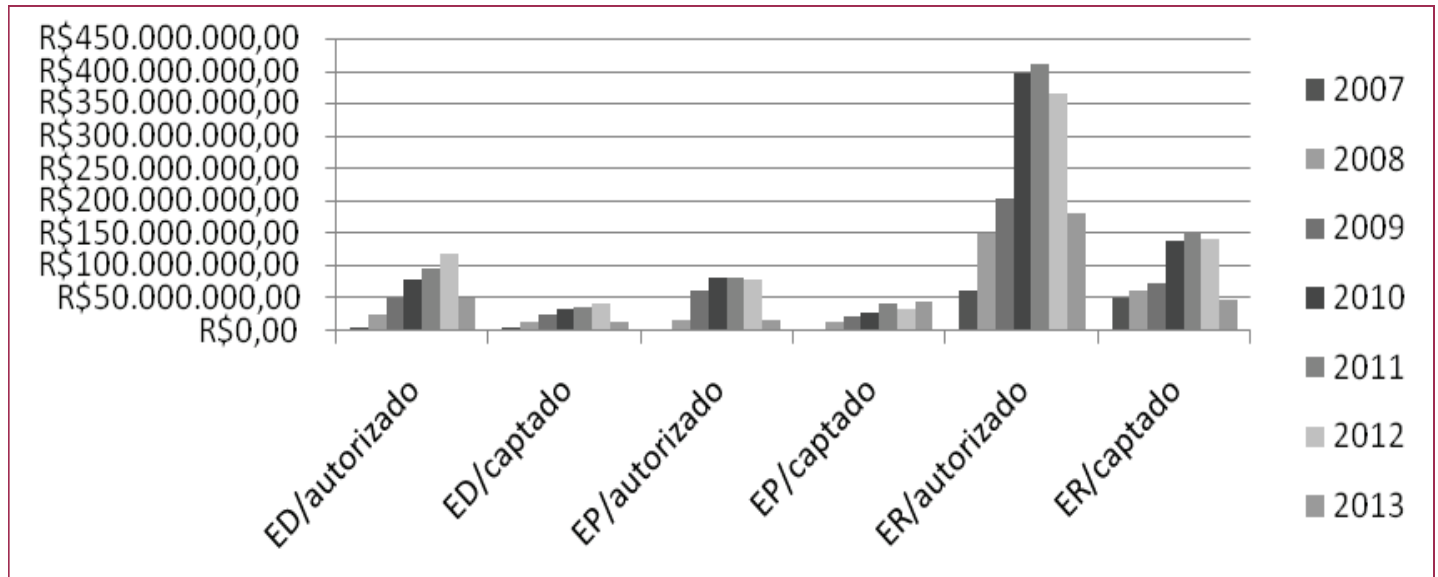

Fonte: Ministério do Esporte. Elaboração dos autores (2014).

Conforme 0 § $1^{\circ}$ do art. 21 do Decreto $n^{\circ}$. 6.180/2007, que regulamentou a LIE, a Comissão Técnica do ME, no momento de análise das propostas, não deve permitir a concentração de recurso "por proponente, por modalidade desportiva ou paradesportiva, por manifestação desportiva ou paradesportiva ou por regiões geográficas nacionais". Portanto, tem-se aí uma infringência ao marco legal.

Outro confronto da execução da LIE com a legislação se estende para a distribuição dos recursos entre as regiões geográficas do país. Conforme demonstra a Figura 4, a 
seguir, a região Sudeste captou mais de $80 \%$ do volume total angariado pelos proponentes.

Figura 4: Distribuição por regiões dos recursos captados via LIE

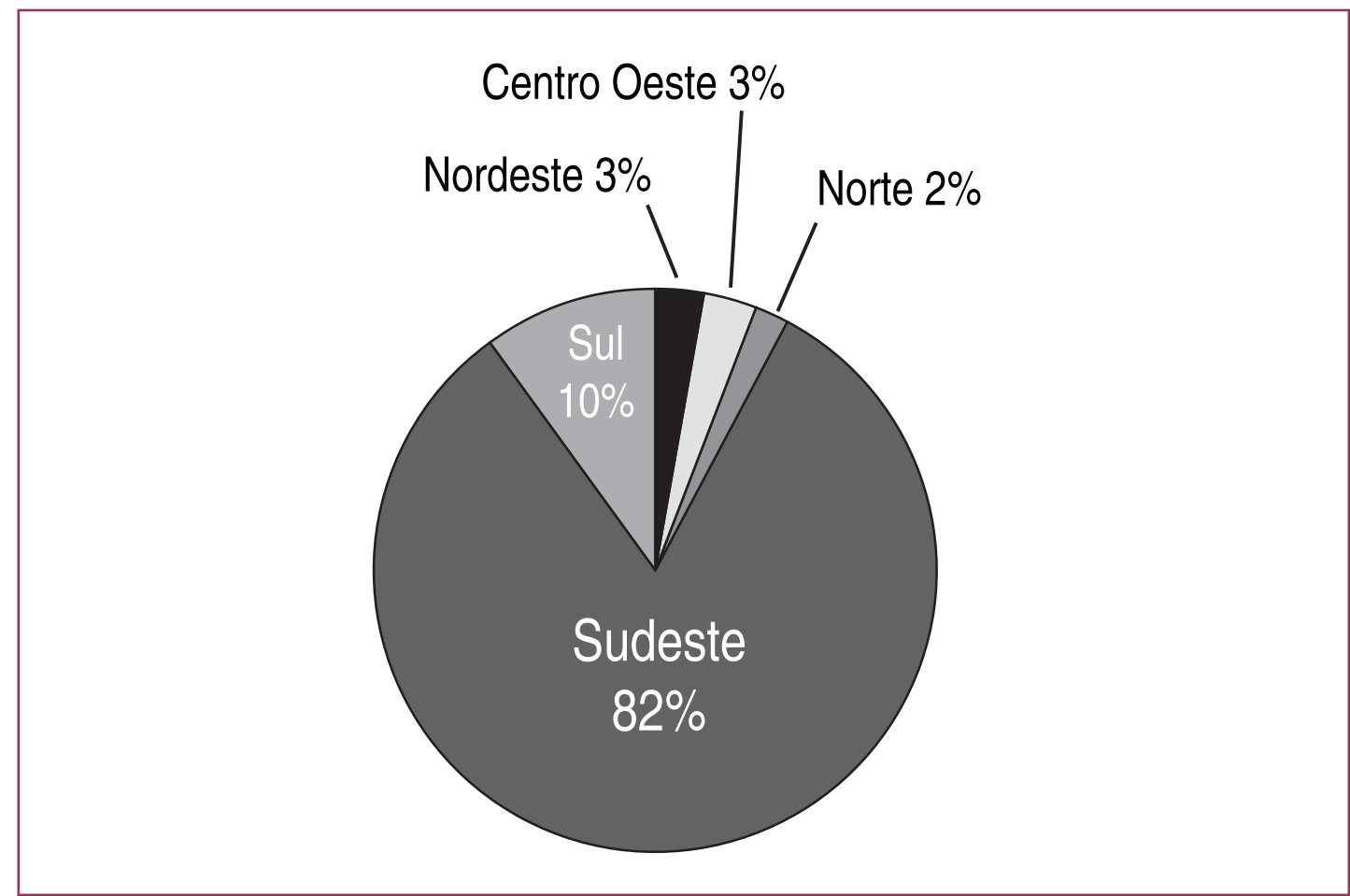

Fonte: Ministério do Esporte. Elaboração dos autores (2014).

A centralização dos recursos na região Sudeste ocorre pela concentração econômica do país nessa localidade e porque as principais entidades esportivas possuem sede nessa região. Destaca-se que as demais fontes de financiamento do esporte também apresentam concentração de recursos nessa mesma localidade do país (MATIAS, 2013).

A distribuição desigual da parcela do fundo público destinado para o esporte amplia a desigualdade de acesso a esse patrimônio humano. Com a destinação de mais recursos para as regiões mais desenvolvidas, inclusive via LIE, temos como resultados menos projetos e infraestrutura em locais que historicamente sofrem com a pequena presença do Estado, como é o caso das regiões Norte e Nordeste.

Outro detalhe que chama a atenção na execução da LIE é a concentração de recursos por proponentes - os principais captadores são os grandes clubes sociais, os clubes de futebol profissional, as associações e institutos de ex-atletas, o Comitê Olímpico Brasileiro (COB) e as confederações (em especial, aquelas com melhor estrutura, como, por exemplo, a de judô e a de desportos aquáticos). As três entidades que mais se beneficiaram foram, respectivamente: a) Esporte Clube Pinheiros; b) Instituto Passe de Mágica; c) Círculo Militar ${ }^{8}$. Estas se apropriaram de quase $15 \%$ do montante captado no período analisado. A primeira recebeu doações de diversas empresas, com destaque para os bancos. $O$ valor auferido somou quase $\mathrm{R} \$ 60 \mathrm{mi}$ Ihões. A segunda conseguiu praticamente $\mathrm{R} \$ 37,5$ milhões somente com a Petrobras; 0 Circulo 
Militar recebeu mais $\mathrm{R} \$ 30,2$ milhões, tendo com principal parceira a empresa de mineração Vale.

Ainda sobre a distribuição dos recursos, cabe destacar o COB, em quarto lugar, com mais de $\mathrm{R} \$ 30$ milhões, praticamente todo da Petrobras. A referência ao COB é importante porque o referido Comitê é a principal entidade do esporte nacional e possui outras fontes de financiamento, principalmente públicas, e, como as outras três entidades, possui ampla visibilidade no cenário nacional. Logo, é necessário questionar se estas não teriam capacidade de atrair patrocínio independente da LIE. Em caso afirmativo, confronta-se com o disposto no $\S 2^{\circ}$ do art. 24 do Decreto $n^{\circ}$. 6.180/2007. Ou seja, é vedado conceder incentivos a projeto desportivo "em que haja comprovada capacidade de atrair investimentos". Portanto, aqueles proponentes e tantas outras não deveriam pleitear recursos por meio da LIE.

De outra forma, o poder público, por meio das prefeituras, secretarias estaduais e universidades, captou somente $1,3 \%$ do total. As entidades privadas e não governamentais conseguiram $98,7 \%$ do volume total da renúncia fiscal.

Portanto, se as instituições públicas ainda não "descobriram" a LIE para financiar seus projetos, os institutos, as associações, as federações e tantas outras entidades esportivas que se multiplicaram nas últimas décadas são justamente quem mais se beneficiam com a captação de recursos via LIE.

Desse modo, fica visível o fato de a LIE beneficiar entidades/atores que historicamente são atendidos pelo Estado e que apenas de forma retórica, para captar mais recursos públicos, consideram o fenômeno esportivo como direito. Quando na verdade as entidades esportivas estão alinhadas à lógica do esporte como um não direito (CASTELLANI FILHO, 2013).

Além da concentração de recursos, por manifestação esportiva, por região geográfica e por proponente, identifica-se ainda a centralização de recursos em modalidades. Somente os clubes de futebol profissional detêm $8 \%$ de todo o recurso captado. Na Figura 5 , a seguir, aponta-se os seis clubes de futebol que mais se beneficiaram no período analisado.

Figura 5: Clubes de futebol x recursos captados em milhões de R\$.

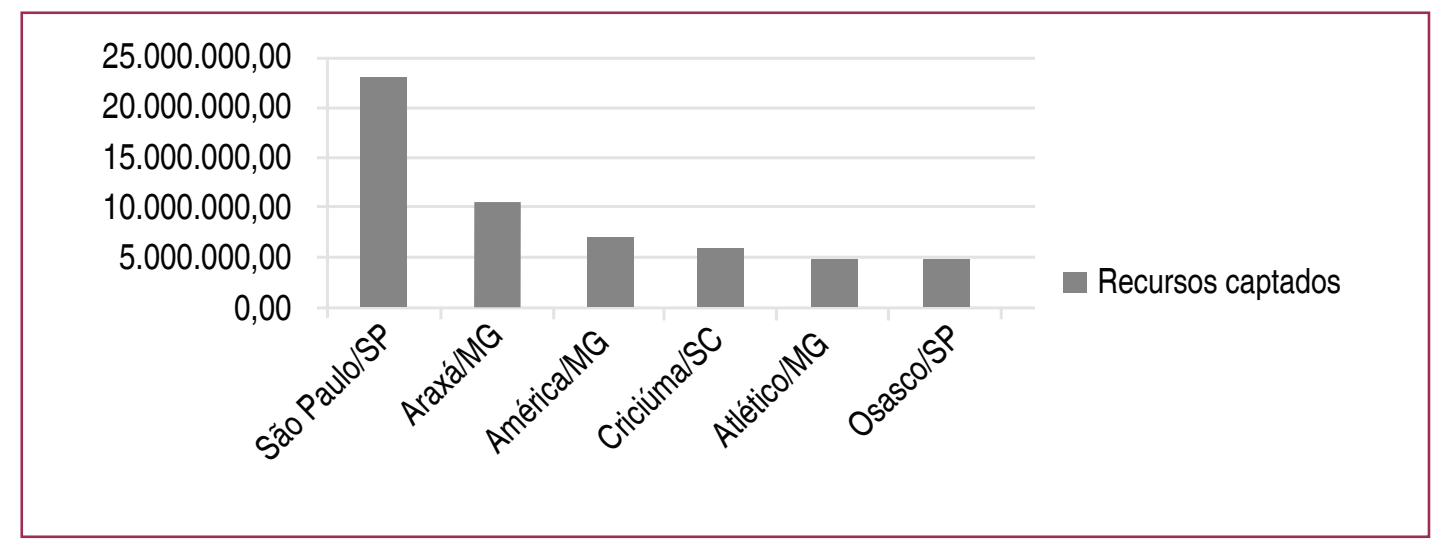

Fonte: Ministério do Esporte. Elaboração dos autores (2014).

Provavelmente, tal montante deve aumentar, uma vez que o Sport Club Corinthians Paulista somente captou $R \$ 2,1$ milhões dos $R \$ 41,16$ milhões de recursos aprovados para 0 patrocínio de seus projetos de formação de base. As modalidades que mais se beneficiaram no 
período foram: futebol, judô e desportos aquáticos. Percebe-se que $12,8 \%$ da renúncia fiscal da LIE foram encaminhados para as referidas modalidades ${ }^{9}$.

Figura 6: Principais modalidades beneficiadas com a LIE em milhões de R\$

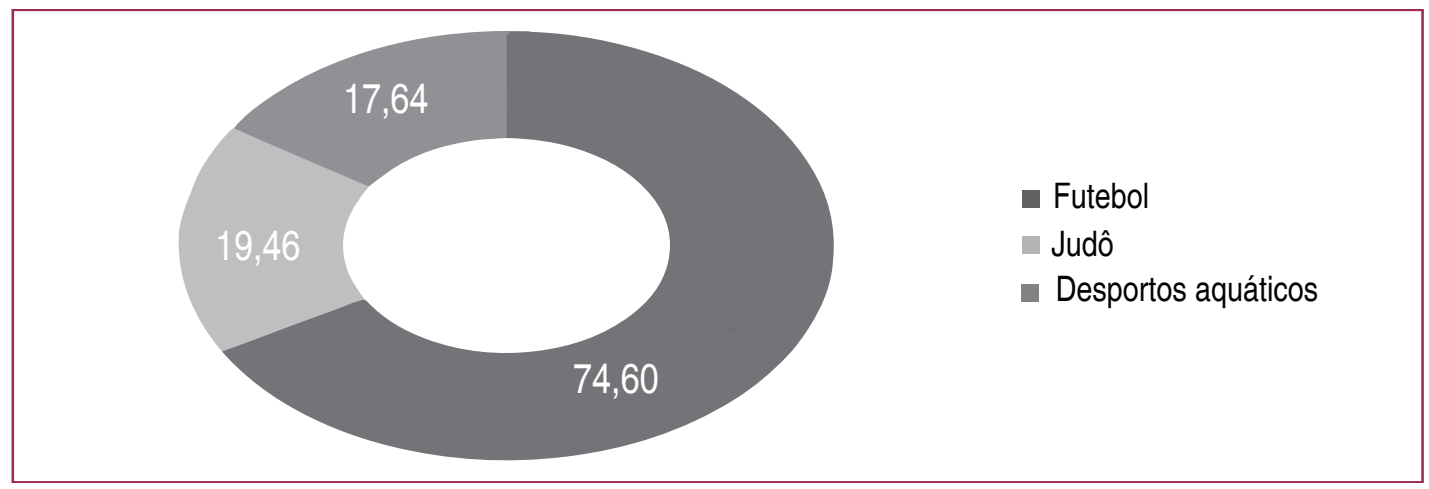

Fonte: Ministério do Esporte. Elaboração dos autores (2014).

Considerando a dimensão continental do país, o quantitativo populacional elevado e a diversidade cultural brasileira a LIE deveria promover uma descentralização dos investimentos tanto no âmbito regional como no apoio das diversas manifestações esportivas. A garantia do acesso ao esporte deve ter como princípio a diversificação das experiências humanas através dos diferentes esportes. Porém, a LIE ao invés de contribuir com a pluralidade da vivência esportiva reforça o financiamento das modalidades mais conhecidas, consumidas e/ou praticadas pelos brasileiros.

Os dados apresentados confirmam que a LIE contribui pouco para a democratização do acesso ao esporte no país. Os interesses mercantis se sobrepõem às necessidades sociais. Tal fato é coerente com a lógica do capital, pois, afinal, sua necessidade básica é garantir visibilidade e ampliação do lucro aos patrocinadores, e não a garantia do acesso aos direitos sociais (MATIAS, 2013).

Se na aparência a LIE é uma fonte de recursos para a democratização do esporte, concretamente se revela desde a sua essência como um mecanismo que atende os interesses da iniciativa privada, retirando do Estado a responsabilidade na implantação das políticas esportivas.

Quanto ao acompanhamento da execução dos projetos, as conclusões do Relatório do Tribunal de Contas da União (TCU, 2013, p. 20) são preocupantes, sobretudo, no que se refere aos apontamentos acerca da fragilidade do monitoramento e da fiscalização:

A atuação incipiente do Ministério do Esporte na fiscalização e no acompanhamento da execução dos projetos, além de descumprir os dispositivos da Lei de Incentivo ao Esporte e do decreto que a regulamenta, abre margem a desvios na execução das despesas, tendo em vista a baixa expectativa de controle por parte dos proponentes.

Portanto, as facilidades de lograr os recursos para a execução dos projetos contrastam com a dificuldade do ME de acompanhar e fiscalizar os termos de parceria. Neste sentido, destaca-se ainda a ausência de qualquer mecanismo de controle democrático e participação social, seja na decisão de aprovação das propostas, seja no acompanhamento da execução.

9 Ressalta-se que estão sendo considerados somente os recursos captados pelos clubes de futebol profissional e as confederações das modalidades de judô e esportes aquáticos (natação, polo aquático, saltos ornamentais, nado sincronizado e maratona aquática). 


\section{CONSIDERAÇÕES FINAIS}

Um dos motivos para a criação da LIE foi a ampliação dos recursos para as políticas esportivas. Nesse sentido, não há dúvida que a Lei vem cumprindo sua missão, inclusive com crescimento do volume captado em todos os anos, com exceção de 2012. Porém, isso pouco contribui para a democratização dessa prática social. Afinal, os dados revelam a concentração de recursos no esporte de rendimento (ER), centralizando-o em algumas entidades, regiões e modalidades esportivas.

É evidente o privilégio concedido à manifestação do ER entre os projetos aprovados, inclusive com a destinação majoritária de recursos a entidades federais de administração do esporte (privadas). Nesse sentido, ficou claro que alguns atores/entidades beneficiados pela LIE são os mesmos que desde a década de 1940 se apropriam de diversas formas do fundo público para desenvolver seus projetos (CASTELLANI FILHO, 2013).

$\mathrm{O}$ investimento prioritário no $\mathrm{ER}$ significa para as empresas retorno de mídia e aumento do consumo passivo do esporte, o que acaba privilegiando algumas entidades que historicamente são beneficiados pelo Estado. Quanto à decisão das empresas de apoiar projetos de esporte participação e esporte educacional, o objetivo se relaciona mais com a imagem de empresa socialmente responsável do que com a garantia de direitos. Nesse sentido, a atitude das empresas pode significar para os moradores de comunidades pobres "[...] um ato de heroísmo e para os doadores, além de um ganho material, o exercício da hegemonia" (SOUSA, 2011, p. 113).

As escolhas das empresas e das pessoas físicas se pautam não pelo interesse coletivo, mas individual. A preocupação é com a ampliação do capital econômico e não com o atendimento das necessidades da população de acesso aos bens esportivos. $O$ que é coerente com a lógica das leis de incentivo, afinal, quem define as prioridades não é o Estado, ainda que o recurso utilizado seja público, a deliberação e as escolhas são de responsabilidade das empresas.

Conclui-se que a renúncia fiscal para o esporte não significa a "segunda revolução" para o setor, como disse o ex-Ministro do Esporte Agnelo Queiroz, mas se caracteriza, em verdade, como uma "contrarrevolução", pois, em sua essência, diminui a presença do Estado no desenvolvimento de políticas públicas, e na sua execução amplia os recursos para os atores que historicamente são privilegiados pelo Estado.

\section{REFERÊNCIAS}

AGNELO pede na Câmara aprovação da lei de incentivo fiscal para o esporte. Brasília, DF: Ministério do Esporte, 2003. Disponível em: <http://www.esporte.gov.br/index.php/institucional/futebol-e-direitosdo-torcedor/torcida-legal/consegue/119-noticias-lie/42582-agnelo-pede-na-camara-aprovacao-da-leide-incentivo-fiscal-para-o-esporte>. Acesso em: 3 mar. 2013.

AUGUSTIN, André Coutinho. A farsa das leis de incentivo: o neoliberalismo e o impacto na política cultural brasileira. Porto Alegre, 2010. 83f. Monografia (Graduação)- Faculdade de Ciências Econômicas da UFRGS. Porto Alegre, 2010.

BASTIDAS, Marina Gallego; BASTOS, Flávia da Cunha. A Lei de Incentivo Fiscal para o desporto e a formação de atletas no Brasil. Revista Intercontinetal de Gestão Desportiva, Porto, v.1, n.2, p. 111-121, jul/dez. 2011. 
BOSCHETTI, Ivanete. Avaliação de políticas, programas e projetos sociais. In: Serviço Social:

Direitos Sociais e Competências Profissionais. Brasília, Conselho Federal de Serviço Social, 2009, p. 1-16.

BRASIL. Lei no 3.199 de 14 de abril de 1941, Estabelece as bases de organização dos desportos em todo o país. Rio de Janeiro, RJ, 14 abr. 1941. Disponível em: < http://www.planalto.gov.br/ccivil 03/ decreto-lei/1937-1946/Del3199.htm>. Acesso em: 11 nov. 2013.

BRASIL. Decreto no 594 de 27 de maio de 1969, Institui a Loteria Esportiva Federal e dá outras providências. Brasília, DF, 27 maio 1969. Disponível em: < https://www.planalto.gov.br/ccivil_03/ decreto-lei/1965-1988/Del0594.htm>. Acesso em: 11 nov.2013.

BRASIL. Decreto no 66.118 de 26 de janeiro de 1970, Regulamenta o disposto no Decreto no 594 de 27 de maio de 1969, Institui a Loteria Esportiva Federal. Brasília, DF, 26 jan. 1970. Disponível em: <https://www.planalto.gov.br/ccivil 03/decreto/1970-1979/D66715.htm>. Acesso em: 11 nov.2013.

BRASIL. Lei no 6.251 de 8 de outubro de 1975, Institui normas gerais sobre desportos, e dá outras providências. Brasília, DF, 08 out. 1975. Disponível em: <http://www6.senado.gov.br/legislacao/ ListaPublicacoes.action?id=205630>. Acesso em: 8 nov. 2012.

BRASIL. Decreto no 80.228 de 25 de agosto de 1977, Regulamenta a Lei no 6.251 de 08 de outubro de 1985, Institui normas sobre o desporto e dá outras providências. Brasília, DF, 8 out. 1985. Disponível em:<https://www.planalto.gov.br/ccivil 03/decreto/1970-1979/d80228.htm>. Acesso em: 11 nov.2013.

BRASIL. Lei no 8.313 de 23 de dezembro de 1991, Restabelece princípios da Lei $n^{\circ} 7.505$, de 2 de julho de 1986, institui o Programa Nacional de Apoio à Cultura (Pronac) e dá outras providências. Brasília, DF, 23 dez. 1991. Disponível em: <http://www.planalto.gov.br/ccivil 03/leis/l8313cons.htm>. Acesso em: 15 nov. 2013.

BRASIL. Lei no 8.672 de 6 de julho de 1993, Institui normas gerais sobre desportos e dá outras providências. Brasília, DF, 06 jul. 1993. Disponível em: < http://www3.dataprev.gov.br/sislex/ paginas/42/1993/8672.htm>. Acesso em: 10 nov. 2012.

BRASIL. Lei no 8.685 de 20 de julho de 1993, Cria mecanismos de fomento à atividade audiovisual e dá outras providências. Brasília, DF, 20 jul. 1993. Disponível em: <http://www.planalto.gov.brl ccivil_03/leis/l8685.htm>. Acesso em: 11 nov. 2013.

BRASIL. Lei no 9.615 de 24 de março de 1998, Institui normas gerais sobre desporto e dá outras providências. Brasília, DF, 24 mar. 1998. Disponível em: <http://www.planalto.gov.br/ccivil_03/Leis/ L9615consol.htm>. Acesso em: 13 nov. 2012.

BRASIL. Lei no 10.264 de 16 de julho de 2001, Acrescenta inciso e parágrafos ao art. 56 da Lei no 9.615, de 24 de março de 1998, Institui normas gerais sobre desporto. Brasília, DF, 16 jun. 2001. Disponível em: <http:// www.planalto.gov.br/ccivil_03/leis/leis_2001/L10264.htm>. Acesso em: 13 nov.2012.

BRASIL. Lei no 10.671 de 15 de maio de 2003, Dispõe sobre o Estatuto de Defesa do Torcedor e dá outras providências. Brasília, DF, 15 maio 2003. Disponível em: < http://www.planalto.gov.br/ccivil_03/ Leis/L9615consol.htm>. Acesso em: 13 nov. 2012.

BRASIL. Lei no 10.891 de 09 de julho de 2004, Institui a Bolsa-Atleta. Brasília, DF, 9 jul. 2004.

Disponível em:<www.planalto.gov.br/ccivil 03/ ato2004-2006/2004/lei//10.891.htm>. Acesso em:11 nov.2013.

BRASIL. CONFERÊNCIA NACIONAL DO ESPORTE, 1., 2004. Brasília, DF. Documento final da I CNE: Esporte, lazer e desenvolvimento humano. Brasília, DF: Ministério do Esporte, 2006. 28p. Disponível em: < http://www2.esporte.gov.br/conferencianacional/arquivos/teseFinal.pdf >. Acesso em: 13 nov. 2013. 
BRASIL. Lei no 11.345 de 14 de setembro de 2006, Dispõe sobre a instituição de concurso de prognóstico destinado ao desenvolvimento da prática desportiva, a participação de entidades desportivas da modalidade futebol nesse concurso e o parcelamento de débitos tributários e para com o Fundo de Garantia do Tempo de Serviço - FGTS; altera as Leis nos 8.212, de 24 de julho de 1991, e 10.522, de 19 de julho de 2002; e dá outras providências. Brasília, DF, 14 set. 2006. Disponível em:<https://www. planalto.gov.br/ccivil 03/ Ato2004-2006/2006/Lei/L11345.htm>. Acesso em: 13 nov. 2012.

BRASIL. Lei no 11.438 de 29 de dezembro de 2006, Dispõe sobre incentivos e benefícios para fomentar as atividades de caráter desportivo e dá outras providências. Brasília, DF, 29 dez. 2006. Disponível em: <http://www.planalto.gov.br/ccivil_03/_ato2004-2006/2006/lei/l11438>. Acesso em: 13 nov. 2012.

BRASIL. CONFERÊNCIA NACIONAL DO ESPORTE, 2., 2006. Brasília, DF. Documento final da II CNE: Construindo o Sistema Nacional do Esporte. Brasília, DF: Ministério do Esporte, 2006. 26p. Disponível em: <http://www2.esporte.gov.br/conferencianacional/conferencia2/documentoFinal.jsp >. Acesso em: 12 nov. 2013.

BRASIL. Lei no 11.487 de 15 de junho de 2007, Altera a Lei no 11.196, de 21 de novembro de 2005, para incluir novo incentivo à inovação tecnológica e modificar as regras relativas à amortização acelerada para investimentos vinculados a pesquisa e ao desenvolvimento. Brasília, DF, 15 jun. 2007. Disponível em:<http://www.planalto.gov.br/ccivil 03/ ato2007-2010/2007/lei//11487.htm>. Acesso em: 11 nov.2013.

BRASIL. Decreto ${ }^{\circ} 6.180$ de 03 de agosto de 2007, Regulamenta a Lei no 11.438 , de 29 de dezembro de 2006, que trata dos incentivos e benefícios para fomentar as atividades de caráter desportivo. Brasília, DF, 3 ago. 2007. Disponível em: $<$ http://www.planalto.gov. br/ccivil_03/_Ato2007-2010/2007/Decreto/D6180.htm>. Acesso em: 11 nov. 2013.

BRASIL. CONFERÊNCIA NACIONAL DO ESPORTE, 3., 2010, Brasília, DF. Documento final da III CNE: Por um time chamado Brasil. Brasília, DF: Ministério do Esporte, 2010. 86 p. Disponível em: <http://portal.esporte.gov.br/conferencianacional/conferencia3.jsp>. Acesso em: 12 nov. 2013.

BRASIL. Projeto de Lei no 5.036-A, de 29 de agosto 2013, Altera a Lei no 11.438, de 29 de dezembro de 2006 para dispor sobre o período e os limites para a dedução do imposto de renda devido, dos valores despendidos a título de patrocínio ou doação, no apoio direto a projetos desportivos e paradesportivos. Brasília, DF, 29 ago. 2013. Disponível em: <http://www.camara.gov.br/ proposicoesWeb/prop mostrarintegra;jsessionid=28B3C722COC >. Acesso em: 10 nov. 2013.

BRASIL. Tribunal de Contas da União. Relatório de auditoria. Renúncia fiscal na área cultural. Auditoria decorrente do acórdão 1.481/2010-plenário. Deficiência na análise de projetos, na concessão, no acompanhamento da execução, na prestação de contas e na gestão de renúncia fiscal. Determinações. Recomendação. Comunicações. Brasília, DF, 30 jan. 2013. Disponível em: <http:// sistemas.cgu.gov.br/relats/uploads/RA244754>. Acesso em: 15 jun.2013.

BUENO, Luciano. Políticas públicas do esporte no Brasil: razões para o predomínio do alto rendimento. São Paulo, 2008. 200f. Tese (doutorado)- Escola de Administração de Empresas de São Paulo. Fundação Getúlio Vargas, São Paulo, 2008.

CASTELLANI FILHO, Lino. Educação Física, Esporte e Lazer: Reflexões nada aleatórias. Campinas, SP: Autores Associados, 2013.

CASTELLANI FILHO, LINO. O Estado brasileiro e os direitos sociais: o esporte. In: GARCIA, Carla Cristina; HÚNGARO, Edson Marcelo; DAMASCENO, Luciano Galvão (Orgs.). Estado, política e emancipação humana: lazer, educação, esporte e saúde como direitos sociais. Santo André: Alpharrabio, 2008, p.129-144.

CAVAZZONI, Pedro Bataglioli; BASTOS, Flávia da Cunha; KURLE, Giovani. Lei de Incentivo ao 
Aires, n.15, n. 146, julho de 2010. Disponível em: <http://www.efdeportes.com/efd146/lei-de-incentivoao-esporte-captacao-de-recursos.htm>. Acesso em: 15 jun. 2013.

FIORI, José Luis. Estado do Bem Estar Social: padrões e crises. São Paulo: Instituto de Estudos Avançados da Universidade de São Paulo, 1991.

FRANÇA JUNIOR, Nelson da Rocha; FRASSON, Antônio Carlos. Lei de incentivo ao esporte: uma forma de inovação tecnológica na captação de recursos financeiros para o esporte no município de Ponta Grossa- Panorama 2000-2009. Revista gestão industrial, Ponta Grossa, v. 6, n. 3, p. 203-217, 2010.

JUNIOR, Newton N. Gomes; PEREIRA, Potyara A. P. Necessidades do capital x versus Necessidades Humanas no capitalismo contemporâneo: uma competição desigual. Argumentum, Vitória, v. 5, n.1, p.50-65, jan./jun. 2013.

MANHÃES, Eduardo Dias. Política de esportes no Brasil. 2. ed.. Rio de Janeiro: Graal, 2002.

MATIAS, Wagner Barbosa Matias. 0 enigma olímpico: o controvertido percurso da política esportiva no governo Lula. Brasília, 2013. 199f. Dissertação (Mestrado), Faculdade de Educação Física. Universidade de Brasília, Brasília, 2013.

OLIVEIRA, Francisco de. Os Direitos do antivalor: a economia política da hegemonia imperfeita. São Paulo: Vozes, 1998.

PEREIRA, Potyara A. P. Política social: temas e questões. 3.ed. São Paulo: Cortez, 2011.

PIVA, Glauber. Cultura: políticas públicas e novas visibilidades. In: SADER, Emir. 10 anos de governos pós-neoliberais no Brasil: Lula e Dilma. São Paulo: Flacso, 2013, p.285-303.

POULANTZAS, Nicos. 0 Estado, o poder, o socialismo. 4. ed. São Paulo: Paz e Terra, 2000.

SALVADOR, Evilásio. Crise do Capital e Socorro do Fundo Público. In: BOSCHETTI, I.; BEHRING, E.; SANTOS, S.; MIOTO, R.. (Org.). Capitalismo em crise, política social e direitos. São Paulo: Cortez, 2010. v. 1, p. 35-63.

SOUSA, Carlos Eduardo de. A política nacional de esporte no Brasil contemporâneo como estratégia para educar o consenso. Juiz de Fora, 2011. 144f. Dissertação (Dissertação de Mestrado em Educação), Faculdade de Educação, UFJF. Rio de Janeiro, 2011. 